\title{
CORRECTION \\ Correction: Extraversion personality, perceived health and activity participation among community-dwelling aging adults in Hong Kong
}

\author{
Daniel W. L. Lai, Nan Qin
}

The first author, Daniel W. L. Lai, is incorrectly noted as the corresponding author. The correct corresponding author is Nan Qin. Dr. Qin’s email address is: nanqin@gdufe.edu.cn.

\section{Reference}

1. Lai DWL, Qin N (2018) Extraversion personality, perceived health and activity participation among community-dwelling aging adults in Hong Kong. PLoS ONE 13(12): e0209154. https://doi.org/10.1371/ journal.pone.0209154 PMID: 30540853

Gopenaccess

Citation: Lai DWL, Qin N (2020) Correction: Extraversion personality, perceived health and activity participation among community-dwelling aging adults in Hong Kong. PLOS ONE 15(1): e0227896. https://doi.org/10.1371/journal. pone.0227896

Published: January 13, 2020

Copyright: ๑ 2020 Lai, Qin. This is an open access article distributed under the terms of the Creative Commons Attribution License, which permits unrestricted use, distribution, and reproduction in any medium, provided the original author and source are credited. 